\title{
Primary signet ring cell carcinoma of the prostate
}

\author{
Whi-An Kwon, MD; Tae Hoon Oh, MD; Sung Hoon Ahn, MD; Jea Whan Lee, MD; Seung Chol Park, MD
}

Department of Urology, Wonkwang University College of Medicine, Institute of Wonkwang Medical Science, Iksan, Republic of Korea

Cite as: Can Urol Assoc J 2013;7(11-12):e768-71. http://dx.doi.org/10.5489/cuaj.630 Published online November 8, 2013.

\section{Abstract}

A 61-year-old Korean man was referred to our institution because of high prostate-specific antigen (PSA) $(8.1 \mathrm{ng} / \mathrm{mL})$ and frequency, nocturia that had lasted for the previous 4 months. The first transrectal ultrasonography (TRUS)-guided prostate biopsy result was benign prostatic hyperplasia. About 3 years later, the patients revisited our institute for elevated PSA $(14.7 \mathrm{ng} / \mathrm{mL})$ and back pain. The patient underwent a second TRUS-guided prostate biopsy. Histological examination and immunohistochemical staining showed a signet ring cell carcinoma (SRCC). Also there were multiple bony metastasis. Androgen deprivation therapy (ADT) was started. Nine months later, the patient was diagnosed with hormone refractory prostate cancer and the ADT was changed into docetaxel chemotherapy. The patient died after 2 cycles of chemotherapy. We report this case of a SRCC of the prostate and review the literature.

$\mathrm{S}$ ignet ring cell carcinoma (SRCC) of the prostate is an uncommon tumour characterized by an intracytoplasmic vacuole compressing the nucleus into a crescent shape at the cellular level. Although SRCC is primarily found in the stomach and colon, it can also be found in the pancreas, breast, thyroid, bladder, and prostate. ${ }^{1}$ SRCC of the prostate, an aggressive subtype of adenocarcinoma, requires careful diagnosis via thorough evaluation and specialized staining processes. Only 1 case of primary SRCC of the prostate has thus far been reported in Korea. ${ }^{2}$ This report describes a second case of a primary SRCC of the prostate in Korea.

\section{Case report}

At October 2008, a 61-year-old man was referred to our institution because of high prostate-specific antigen (PSA) $(8.1 \mathrm{ng} / \mathrm{mL})$ and frequency, nocturia for the previ- ous 4 months. The patient had no concomitant medical or familial history of any malignancy. A physical examination, including a digital rectal examination (DRE), revealed an enlarged prostate gland and not palpable as firm, indurated nodules. A serum PSA level of $9.2 \mathrm{ng} / \mathrm{mL}$ was determined, and a transrectal ultrasonography (TRUS) of the prostate gland showed a volume of 38 cc without hypoechoic lesion in prostate. TRUS-guided prostate biopsy was performed. The result of prostate biopsy was benign prostatic hyperplasia $(\mathrm{BPH})$. And $\mathrm{BPH}$ medication treatment was continued at private clinic. At August 2011, because the patient experienced back pain, a chest computed tomographic (CT) scan was performed and showed sternum and spine bone metastasis at private clinic. After hospital admission his serum PSA increased to $14.7 \mathrm{ng} / \mathrm{mL}$. The size of the prostate was $27 \mathrm{~mL}$ on the TRUS and hypoechoic lesions were in left transitional zone TRUS-guided prostate biopsy was performed and a SRCC-like lesion, suggestive of adenocarcinoma, was found in 1 of the 12 pieces with $20 \%$ of tumour volume.

Pathologically, the tumour cells had marked cytological and nuclear pleomorphism, admixed with spindle cells and histiocyte-like cells. Cellularity was high and cellular atypia, nuclear pleomorphism, mitoses, abnormal mitoses and areas of tumour necrosis were observed (Fig. 1). Immunohistochemical staining was performed for accurate diagnosis. Pan-cytokeratin (Pan-CK) staining was diffuse 2 positive, PSA staining was focal 3 positive, high molecular weight cytokeratin (HMW-CK) was negative, CD 68 staining was positive on scattered histiocytes and P504S was focally 1 positive (Fig. 2a, Fig. 2b, Fig. 2c, Fig. 2d). Undifferentiated high-grade sarcoma was the diagnosis of exclusion.

A CT scan, magnetic resonance imaging (MRI) of the prostate and a radionucleotide bone scan (Fig. 3) were conducted to evaluate the stage of prostate cancer. The $\mathrm{CT}$ and radionucleotide bone scan revealed multiple bony metastasis. The findings of gastrointestinal $(\mathrm{Gl})$ and colon fiberoscopy showed no evidence of tumour. The patient was 


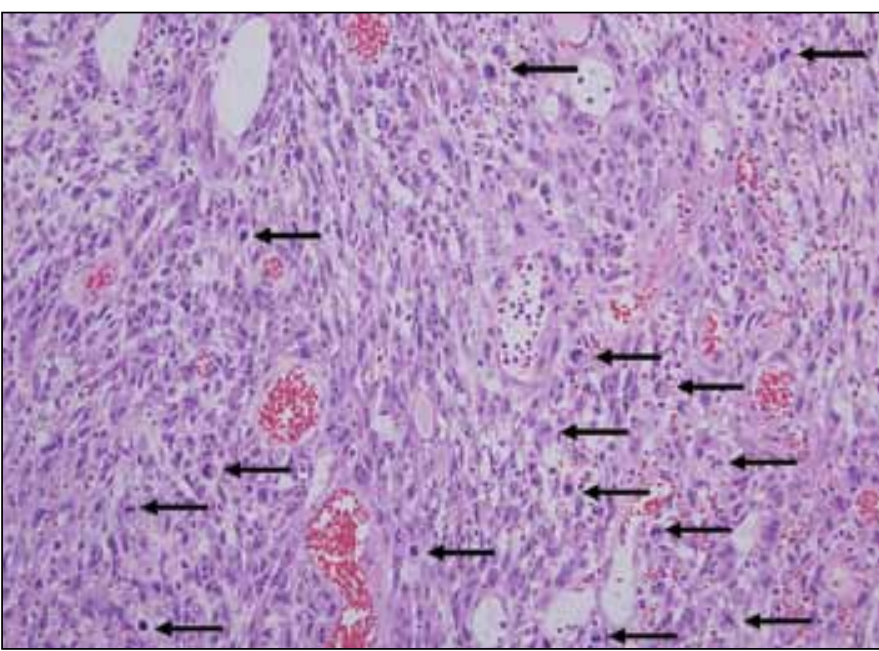

Fig. 1. A transrectal ultrasonography-guided prostate biopsy shows signet ring cell carcinoma-like lesion, suggestive of adenocarcinoma. The tumour is composed of an admixture of spindled and pleomorphic cells with numerous mitotic figures (arrows) (hematoxylin-eosin $\times 200$ ). diagnosed as having a stage cT2bN0M1b prostatic signet ring cell adenocarcinoma and androgen deprivation therapy (ADT) was started at September 2011. Nine months later, he was diagnosed with hormone refractory prostate cancer (HRPC) and ADT was changed to docetaxel chemotherapy. The patient died after 2 cycles of chemotherapy.

\section{Discussion}

Primary SRCC is very rare; it was first reported in $1979^{3}$ and is estimated to occur in $2.5 \%$ of cases of adenocarcinoma of the prostate. ${ }^{4}$ The term "signet ring cell" is used to describe cells that have had their nuclei displaced by an intracytoplasmic vacuole and a signet-ring configuration. Guerin and colleagues ${ }^{5}$ suggested that SRCC should be classified as a variant of high-grade adenocarcinoma rather than a separate histologic clarification. In support of this proposition, SRCC is often found in the presence of other high-grade prostatic adenocarcinoma patterns. To diagnose primary SRCC of the prostate, SRCC should contain

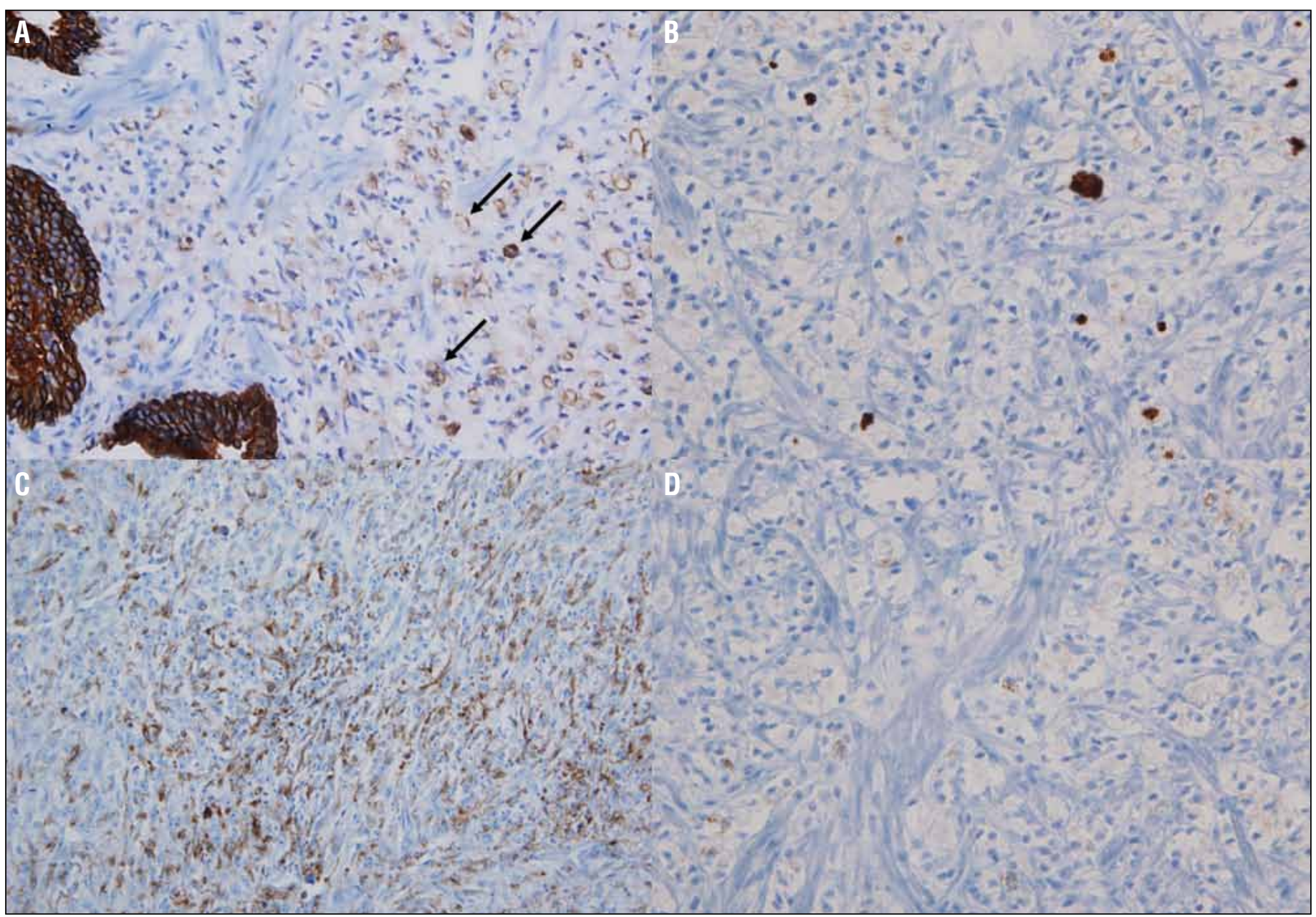

Fig. 2. (A) Immunohistochemical staining shows that pan-cytokeratin (pan-CK) staining was diffuse 2 positive ( $\times 400)$. (B) Prostate-specific antigen staining was focal 3 positive $(\times 400)$. (C) CD 68 staining was positive on scattered histiocytes $(\times 200)$. (D) P504S was focally 1 positive $(\times 400)$. 


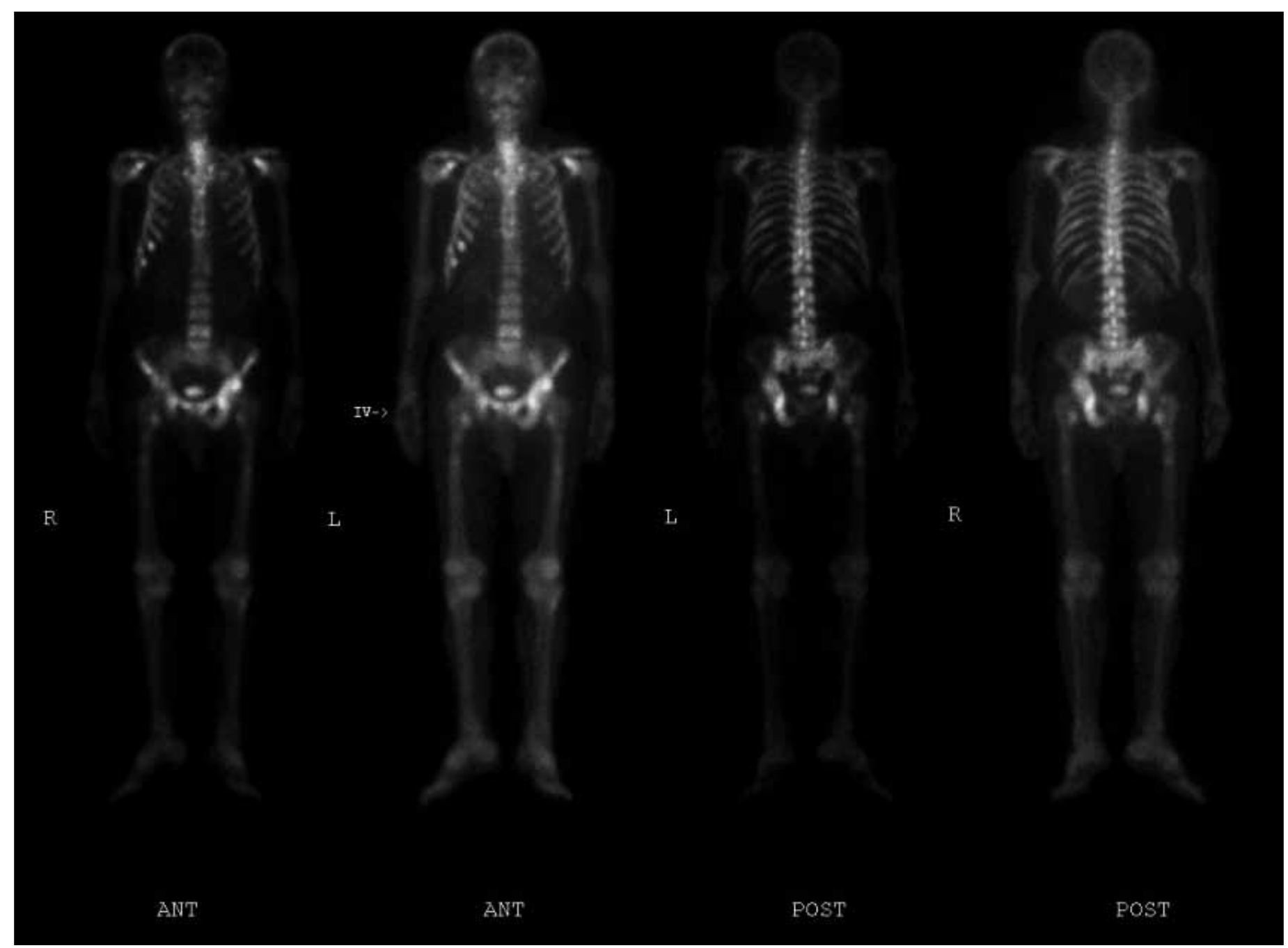

Fig. 3. Whole body radionucleotide bone scan shows multiple bony metastases.

more than $25 \%$ of the tumour. ${ }^{4}$ Only a few cases of prostate cancer have been mucin-positive signet cells. Before making a final diagnosis of a primary SRCC of the prostate, many false-positives should be excluded. In fact, certain histologic appearance can be similar to the signet ring cell, such as vacuolated lymphocytes and altered smooth muscle cells after radiotherapy or hormone therapy. The prostatic lymphomas with infiltrated lymphocytes containing a large cytoplasmic vacuole and an eccentric nucleus may also resemble signet ring cells. ${ }^{6}$ The diagnosis of primary prostatic SRCC of the prostate is certainly a histologic diagnosis that can be done using needle biopsy, endoscopic resection specimens, or prostatectomy specimens.

The workup focuses on differentiating a primary tumour of the prostate from one located in the Gl tract because the $\mathrm{Gl}$ tract is a more common location for signet ring cells. The different origins of $\mathrm{Gl}$ and prostate tumours is significant because the treatment of a metastatic GI primary tumour would require additional and alternative therapies. In our patient, the Gl workup showed no evidence of tumour. Therefore, we assumed that the prostate was the primary source of the tumour.

Clinically, primary SRCC of the prostate have the same classic obstructive and irritative symptoms as other common adenocarcinomas. Based on previously reported cases, the mean age of patients is 68.2 years (range: $50-84){ }^{7}$ Our patient showed frequency, nocturia and was 61 years old at the onset of his symptoms.

Primary SRCCs of the prostate have a poor prognosis even when treated with aggressive therapy. More of these patients present with stage IV disease than with any other stage. Fujita and colleagues ${ }^{7}$ reported that, in primary SRCC of the prostate, the survival rate is about $55 \%$ at 3 years and decreases to $12 \%$ at 5 years. These rates are, however, comparable to the survival rates in the other type of prostatic adenocarcinomas. The same study revealeded that prognosis is only related to the stage of the disease at diagnosis. A stage IV disease is an indicator of poor prognosis. 
The treatment access for SRCC has been similar to access for other traditional adenocarcinomas of the prostate, involving variable combinations of hormonal therapy, radiation, and surgery. Nevertheless, on the basis of the available cases, the effectiveness of hormonal therapy is unpredictable. To date, no definite explanation for this variability has been given; however, Lilleby and colleagues ${ }^{8}$ reported a case of SRCC treated with neoadjuvant hormonal therapy and radiotherapy with a favourable response at 12 months of follow-up. Moreover, Kanematsu and Hiura ${ }^{9}$ reported a case of primary SRCC with an undetectable PSA level 3 years after a radical prostatectomy and preoperative androgen blockade. Akagashi and colleagues ${ }^{10}$ further reported a case of an undetectable PSA level 20 months after treatment with complete androgen blockade. No single treatment modality is ideal for treating SRCC, but we consider that more aggressive multimodal treatment should be considered.

\section{Conclusion}

It is important to clearly differentiate these tumours; this requires careful diagnosis via thorough evaluation and specialized staining processes. Verifing the primary origin is the most significant aspect in their diagnosis. The poor prognosis of these tumours is correlated with the diagnosis at a very late stage. We recommend early, careful assessment for appropriate diagnosis. Also aggressive treatment and close follow-up are crucial to patients with SRCC of the prostate.

Acknowledgements: This study was supported by Wonkwang University in 2013.
Competing interests: Dr. Kwon, Dr. Oh, Dr. Ahn, Dr. Lee and Dr. Park all declare no competing financial or personal interests.

This paper has been peer-reviewed.

\section{References}

1. Warner JN, Nakamura LY, Pacelli A, et al., editors. Primary signet ring cell carcinoma of the prostate. Mayo Clin Proc 2010;85:1130-6. http://dx.doi.org/10.4065/mcp.2010.0463

2. La YH, Park JY, Shin HS, et al. Primary signet ring cell adenocarcinoma of the prostate. Korean I Urol 1989;30:604-6.

3. Smith C, Feddersen RM, Dressler L, et al. Signet ring cell adenocarcinoma of prostate. Urology 1994;43:397-400. http://dx.doi.org/10.1016/0090-4295(94)90089-2

4. Torbenson M, Dhir R, Nangia A, et al. Prostatic carcinoma with signet ring cells: a clinicopathologic and immunohistochemical analysis of 12 cases, with review of the literature. Mod Pathol 1998;11:552-9.

5. Guerin D, Hasan N, Keen CE. Signet ring cell differentiation in adenocarcinoma of the prostate: a study of five cases. Histopathol 1993;22:367-71. http://dx.doi.org/10.1111/j.1365-2559.1993.tb00137.x

6. Kuroda $\mathrm{N}$, Yamasaki I, Nakayama $\mathrm{H}$, et al. Prostatic signet-ring cell carcinoma: case report and literature review. Pathol Int 1999;49:457-61. http://dx.doi.org/10.1046/i.1440-1827.1999.00876.x

7. Fuita K, Sugao $\mathrm{H}$, Gotoh $\mathrm{T}$, et al. Primary signet ring cell carcinoma of the prostate: report and review of 42 cases. Int J Urol 2004;11:178-81. http://dx.doi.org/10.1111/i.1442-2042.2003.00763.x

8. Lilleby $\mathrm{W}$, Axcrona $\mathrm{K}$, Alfsen $\mathrm{GC}$, et al. Diagnosis and treatment of primary signet-ring cell carcinoma of the prostate. Acta Oncol 2007;46:1195-7. hittp://dx.doi.org/10.1080/02841860701367886

9. Kanematsu A, Hiura M. Primary signet ring cell adenocarcinoma of the prostate treated by radical prostatectomy after preoperative androgen deprivation. Int J Urol 1997;4:522-3. http://dx.doi. org/10.1111/i.1442-2042.1997.tb00298.x

10. Akagashi K, Tanda $\mathrm{H}$, Kato $\mathrm{S}$, et al. Signet ring cell carcinoma of the prostate effectively treated with maximal androgen blockade. Int J Urol 2003;10:456-8. http://dx.doi.org/10.1046/j.14422042.2003.00649.x

Correspondence: Dr. Seung Chol Park, Department of Urology, Wonkwang University School of Medicine and Hospital, 344-2, Shinyong-dong, lksan 570-711, Korea; fax: 063-858-1181; sc.park@wonkwang.ac.kr 